\title{
The inflammation patterns of different inflammatory cells in histological structures of hyperplasic prostatic tissues
}

\author{
Yisen Meng ${ }^{1,2,3}$, Wei Yu ${ }^{1,2,3}$, Zhenhua Liu ${ }^{1,2,3}$, Muqiu Zhang ${ }^{1,2,3}$, Yuke Chen ${ }^{1,2,3}$, Shaobo Li ${ }^{4}$, Yu Fan ${ }^{1,2,3}$, \\ Shuai Hu ${ }^{1,2,3}$, Kai Zhang ${ }^{1,2,3}$, Qian Zhang ${ }^{1,2,3}$, Jie Jin ${ }^{1,2,3}$ \\ ${ }^{1}$ Department of Urology, Peking University First Hospital, Beijing, China; ${ }^{2}$ Institute of Urology, Peking University, Beijing, China; ${ }^{3}$ National \\ Research Center for Genitourinary Oncology, Beijing, China; ${ }^{4}$ School of Basic Medicine, Fudan University, Shanghai, China \\ Contributions: (I) Conception and design: Y Meng, J Jin; (II) Administrative support: K Zhang, Q Zhang, S Hu; (III) Provision of study materials or \\ patients: W Yu, Z Liu; (IV) Collection and assembly of data: Y Fan, S Li; (V) Data analysis and interpretation: Y Chen, M Zhang; (VI) Manuscript \\ writing: All authors; (VII) Final approval of manuscript: All authors. \\ Correspondence to: Jie Jin, MD, PhD. Department of Urology, National Urological Cancer Center, Peking University First Hospital and Institute of \\ Urology, Peking University, 8 Xishiku Street, Xicheng District, Beijing 100034, China. Email: jinjie@vip.163.com.
}

Background: The distribution characteristics of inflammatory cells in hyperplastic prostatic tissue and its influences on disease development remain unknown. We aimed to explore the infiltration characteristics of different inflammatory cells in histological structures of benign prostatic hyperplasia (BPH) in combination with clinical data.

Methods: The present study included 76 cases of BPH patients underwent transurethral resection of prostate (TURP). Hematoxylin-eosin staining was performed to identify the degree of general inflammation in prostatic tissues. The infiltration of T-lymphocytes (CD3), B-lymphocytes (CD20), and macrophages (CD68) were recorded by immunohistochemistry.

Results: The present study included $76 \mathrm{BPH}$ patients with the mean age of 69.5 years old (range, 4983 years) and the mean prostate volume of $91.9 \mathrm{~mL}$ (range, 24-218 mL). Periglandular inflammation was the most common pattern, being presented in $94.7 \%$ (72/76) patients, followed by stromal inflammation $(67 / 76,88.2 \%)$ and glandular inflammation $(57 / 76,75.0 \%)$. However, the stroma presented the highest rate of severe inflammation $(14.6 \%)$. And the grades of glandular inflammation and stromal inflammation were independently correlated with prostate volume. T-lymphocytes, B-lymphocytes and macrophages had different infiltrated patterns in histological structures of prostate. And stromal hyperplasia dominated $\mathrm{BPH}$ was only significantly correlated with the T-lymphocytes infiltration condition $(\mathrm{P}=0.001)$. Meanwhile, overweight patients had more severe glandular inflammation in the prostate $(\mathrm{P}=0.010)$. The grade of glandular inflammation could independently increase prostate-specific antigen (PSA).

Conclusions: We characterized infiltrated patterns of different inflammatory cells in histological structures of hyperplasic prostatic tissues from surgically treated BPH specimens. The role of inflammation in BPH development was highlighted by its correlation with the prostate volume, metabolism and PSA level.

Keywords: Benign prostatic hyperplasia (BPH); inflammation; T-lymphocytes; B-lymphocytes; macrophages

Submitted Jan 16, 2020. Accepted for publication Jul 09, 2020.

doi: $10.21037 /$ tau-20-448

View this article at: http://dx.doi.org/10.21037/tau-20-448 


\section{Introduction}

Benign prostatic hyperplasia ( $\mathrm{BPH})$ is the most frequently diagnosed urological disease in ageing men (1). Histologically, BPH is characterized by the excessive proliferation of both epithelial cells and stromal cells within the transitional zone, causing prostate enlargement and lower urinary tract symptoms (LUTS) (2). BPH is chronically progressive and age dependent, which lead to a diminished health-related quality of life (3). The prevalence of BPH usually initiates after 40 years of age and gradually approaches the peak during 60 to 90 years old $(1,3,4)$. The clinical progression of $\mathrm{BPH}$ is recorded, when an elderly man suffers from frequent LUTS or acute urinary retention $(5,6)$.

Multiple risk factors have been proposed to contribute to the development of $\mathrm{BPH}$, including ageing, diet, hormonal alterations, and chronic inflammation $(3,7)$. Although the definite cause of $\mathrm{BPH}$ remains a dilemma, majority of etiological postulates indicate that the chronic histological inflammation plays an indispensable role in the development of BPH $(8,9)$. The role of inflammation in $\mathrm{BPH}$ development is highlighted by the strong correlation between histological inflammation, clinical symptoms, and prostate volume (10). Actually, increased infiltration of macrophages, T-lymphocytes, and B-lymphocytes are frequently detected in prostate tissues from $\mathrm{BPH}$ patients (9-11). According to the published literatures, continuous inflammatory tissue damage and subsequent process of repetitive wound healing cause prominent proliferation of stromal and epithelial cells of the prostate (11). However, the distribution characteristics of inflammatory cells in hyperplastic prostatic tissue and its influences on disease development remain unknown.

In the present study, we investigated the infiltration condition of different inflammatory cells in glandular, periglandular, and stromal sections of hyperplastic prostatic tissues, and analyzed the correlation between infiltrated inflammation pattern and clinical data of $\mathrm{BPH}$ patients. We present the following article in accordance with the STROBE reporting checklist (available at http://dx. doi. org/10. 21037/tau-20-448).

\section{Methods}

The present study included 76 patients who were diagnosed $\mathrm{BPH}$ and underwent transurethral prostatic resection (TURP) from January 2009 to February 2010 in our center. Patients were excluded if they had complaints of perineal, suprapubic or voiding pain, positive urine cultures, catheterization, medication history of $5 \alpha$-reductase inhibitors, prostatic tumor or history of prostatitis and prostate surgery. The PSA test was performed for two times: about one month before surgery at outpatient department and one day before surgery at inpatient ward. And the mean value of PSA was recorded. Patient's prostate size was measured by transrectal ultrasound one day before the TURP surgery. This study was approved by the institutional ethics committee (NO.: 2018-403) of our center. Patient records or information were anonymous and de-identified prior to analysis. Written informed consent was obtained from the patient for publication of this study and any accompanying images. This study was also in line with the Helsinki declaration (as revised in 2013).

$\mathrm{BPH}$ is mainly developed in the transitional zone of the prostate. In TURP, it is the prostate tissues at the transitional zone that are removed and sent for pathological examination. In our center, for every $\mathrm{BPH}$ patient, all the TURP tissues are sent for pathological examination. The TURP specimens were formalin fixed, dehydrated, paraffin-embedded and sliced at $5 \mu \mathrm{m}$ per slice. According to the histopathological classification system for chronic prostatic inflammation proposed by the Chronic Prostatitis Collaborative Research Network (CPCRN) and the International Prostatitis Collaborative Network (IPCN) (11), the histological sections of inflammation were classified as glandular, periglandular, and stromal. The grades of inflammation were characterized by hematoxylineosin (H\&E) staining from 0 to 3 (Table S1).

First, the tissue slices were stained with H\&E. All the $\mathrm{H} \& \mathrm{E}$ sections of one $\mathrm{BPH}$ patient were back to back reviewed of by two pathologists. For each case, the prostatic inflammatory infiltrates in each histological structure (glandular, periglandular and stromal) were recorded by the extent of inflammation (focal, multifocal or diffuse) and the grade of inflammation (mild, moderate and severe). And the most dominant inflammation pattern of one patient was defined as the histological structure with the most extent and grade of inflammation. Then, we chose the tissue slice with the most dominant inflammation pattern for immunohistochemistry (IHC). IHC was performed using antibodies decorating T-lymphocytes (CD3, rabbit polyclonal Ab A0452; antigen retrieval, $\mathrm{pH}$ 6.0; 1:300; Dako; Corp.: Abcam; Cambridge, USA), B-lymphocytes (CD20, mouse monoclonal Ab clone L26; antigen retrieval, pH 6.0; 1/500; Dako; Corp.: Abcam; Cambridge, USA), and 
macrophages (CD68, mouse monoclonal Ab clone 10D6; antigen retrieval, $\mathrm{pH} 6.0 ; 1: 800$; Novocastra-Menarini; Corp.: Abcam; Cambridge, USA). The proportion of T-lymphocytes, B-lymphocytes and macrophages less than $5 \%$ in all cells per high magnification was defined as no infiltration, which was also back to back reviewed by the pathologists.

We used SPSS v21.0 software (Corp.: IBM; Armonk, USA) for statistical description and analysis. The Kolmogorov-Smirnov test determined the normality of the continuous variables. Mean and range presented continuous variables; the Student $t$-test or Mann-Whitney U-test compared the differences between the two groups. Frequency and percentile were used to present categorical or ranked variables; the Fisher exact test was used to test the differences. Logistic regression analysis was performed in multivariate analysis. All reported $\mathrm{P}$ values are two sided, and $\mathrm{P}<0.05$ was considered statistically significant.

\section{Results}

\section{Characteristics of BPH patients}

The present study included $76 \mathrm{BPH}$ patients with the mean age of 69.5 years old (range, $49-83$ years) and the mean body mass index (BMI) of $24.47 \mathrm{~kg} / \mathrm{m}^{2}$ (range, $\left.19.03-38.09 \mathrm{~kg} / \mathrm{m}^{2}\right)$. The mean total prostate volume and preoperative serum prostate-specific antigen (PSA) of the study cohort were $91 \mathrm{~mL}$ (range, 24-218 mL) and $5.86 \mathrm{ng} / \mathrm{mL}$ (range, $0.73-17.97 \mathrm{ng} / \mathrm{mL}$ ). There were 36 patients having hypertension and 9 patients suffering from diabetes. Twenty patients received prostate biopsies before surgery due to the elevated serum PSA.

\section{Characteristics of inflammatory infltration in hyperplasic prostatic tissues}

According to the $\mathrm{H} \& \mathrm{E}$ staining, all the hyperplasic prostatic tissues had inflammatory cells infiltration (Figure 1). There were $23.7 \%(18 / 76)$ patients, $5.3 \%$ (4/76) patients and $11.8 \%(9 / 76)$ patients had no inflammation in glandular, in periglandular and in stromal, respectively. Therefore, periglandular inflammation was the most common histologic type, being presented in $94.7 \%$ of patients, followed by stromal inflammation $(67 / 76,88.2 \%)$ and glandular inflammation $(57 / 76,75.0 \%)$.

In addition, we recorded three grades of inflammatory cells infiltration for different histologic types: mild, moderate and severe. Among the samples with glandular inflammation, mild inflammation accounted for $51.3 \%$ (39/76), moderate inflammation accounted for $22.4 \%$ $(17 / 76)$ and severe inflammation accounted for $1.3 \%(1 / 76)$, respectively. For periglandular inflammation samples, mild inflammation accounted for $46.1 \%(35 / 76)$. Moderate and severe inflammation accounted for $42.1 \%(32 / 76)$ and $6.6 \%$ (5/76). Stromal inflammation was detected in severe degree for $14.5 \%$ (11/76), in moderate grade for $38.2 \%$ (29/76), in mild degree for $35.5 \%$ (27/76).

We also assessed the extent of inflammation of prostate in the present study. The histopathological criteria that we referred was originated from the chronic prostatitis. Different from that of the chronic prostatitis, the extent of inflammation in $\mathrm{BPH}$ is mainly multifocal infiltration and scarcely focal infiltration or diffuse infiltration.

Univariable and multivariable regression were performed to analyze influence factors of prostate volume adjusted for the grades of each inflammatory pattern, age, and complications (Table 1). Univariable regression analysis revealed prostate volume was significantly associated with grading of glandular, periglandular and stromal inflammation, also with age. Multiple regression analysis identified grading of glandular inflammation $(\mathrm{P}=0.015)$ and stromal inflammation $(\mathrm{P}=0.037)$ were independently correlated with prostate volume. The patients had more severe periglandular inflammation tending to have larger prostate volume without reaching statistical significance $(\mathrm{P}=0.082)$.

IHC was performed to further analyze the distribution of different inflammatory cells (Figure 2). We found that there were differences in distribution of the three types of inflammatory cells at glandular $(\mathrm{P}=0.003)$, periglandular $(\mathrm{P}<0.001)$ and stromal $(\mathrm{P}<0.001)$. There were higher rates of T-lymphocytes and macrophages in the glandular infiltration. The proportion of T-lymphocytes and B-lymphocytes was higher in the periglandular infiltration. In the stromal section, the infiltrations of T-lymphocytes and macrophages were more common (Table 2). Then, patients were divided into two groups on the categories of prostatic hyperplasia as glandular hyperplasia dominated and stromal hyperplasia dominated $(12,13)$ (Figure S1). According to the Chi-square test, stromal hyperplasia dominated was only significantly correlated with the condition of stromal T-lymphocytes infiltration $(\mathrm{P}<0.001)$ (Table 3).

We also did further analysis to see if there was a relationship between the specific type of immune 

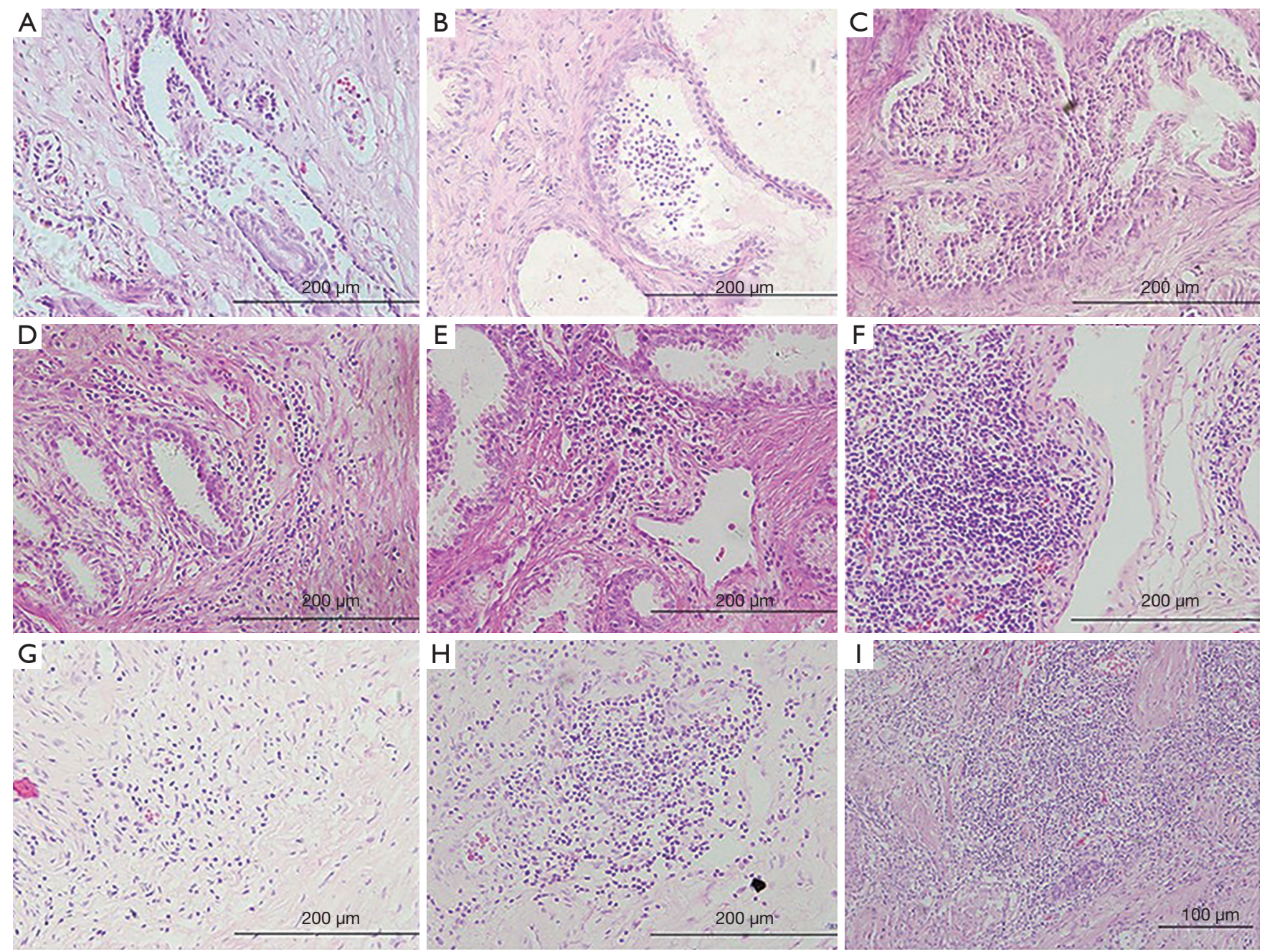

Figure 1 Glandular, periglandular and stromal inflammatory infiltration of varying degrees (H\&E staining, ×200). (A,B,C) Glandular inflammation: (A) grade 1 (mild, in 51.3\% patients); (B) grade 2 (moderate, in 22.4\% patients); (C) Grade 3 (severe, in $1.3 \%$ patients). (D,E,F) Periglandular inflammation: (D) grade 1 (mild, in 46.1\% patients); (E) grade 2 (moderate, in 42.1\% patients); (F) grade 3 (Severe, in $6.6 \%$ patients). (G,H,I) Stromal inflammation: (G) grade 1 (mild, in 35.5\% patients); (H) grade 2 (moderate, in $38.2 \%$ patients); (I) grade 3 (severe, in $14.5 \%$ patients).

Table 1 Univariable and multiple regression analysis of prostate volume

\begin{tabular}{|c|c|c|c|c|}
\hline Variables & \multicolumn{2}{|c|}{ Univariable regression analysis } & \multicolumn{2}{|c|}{ Multivariable regression analysis } \\
\hline Age & 0.323 & $0.004^{*}$ & 0.262 & $0.010^{*}$ \\
\hline Hypertension & 0.228 & $0.047^{*}$ & 0.191 & 0.059 \\
\hline Diabetes & 0.120 & 0.303 & - & - \\
\hline Grading of periglandular inflammation & 0.368 & $0.001^{*}$ & 0.180 & 0.082 \\
\hline Grading of stromal inflammation & 0.337 & $0.003^{*}$ & 0.217 & $0.037^{\star}$ \\
\hline
\end{tabular}

$P$ value was analyzed by univariate or multivariate regression analysis. *, $P<0.05$. 

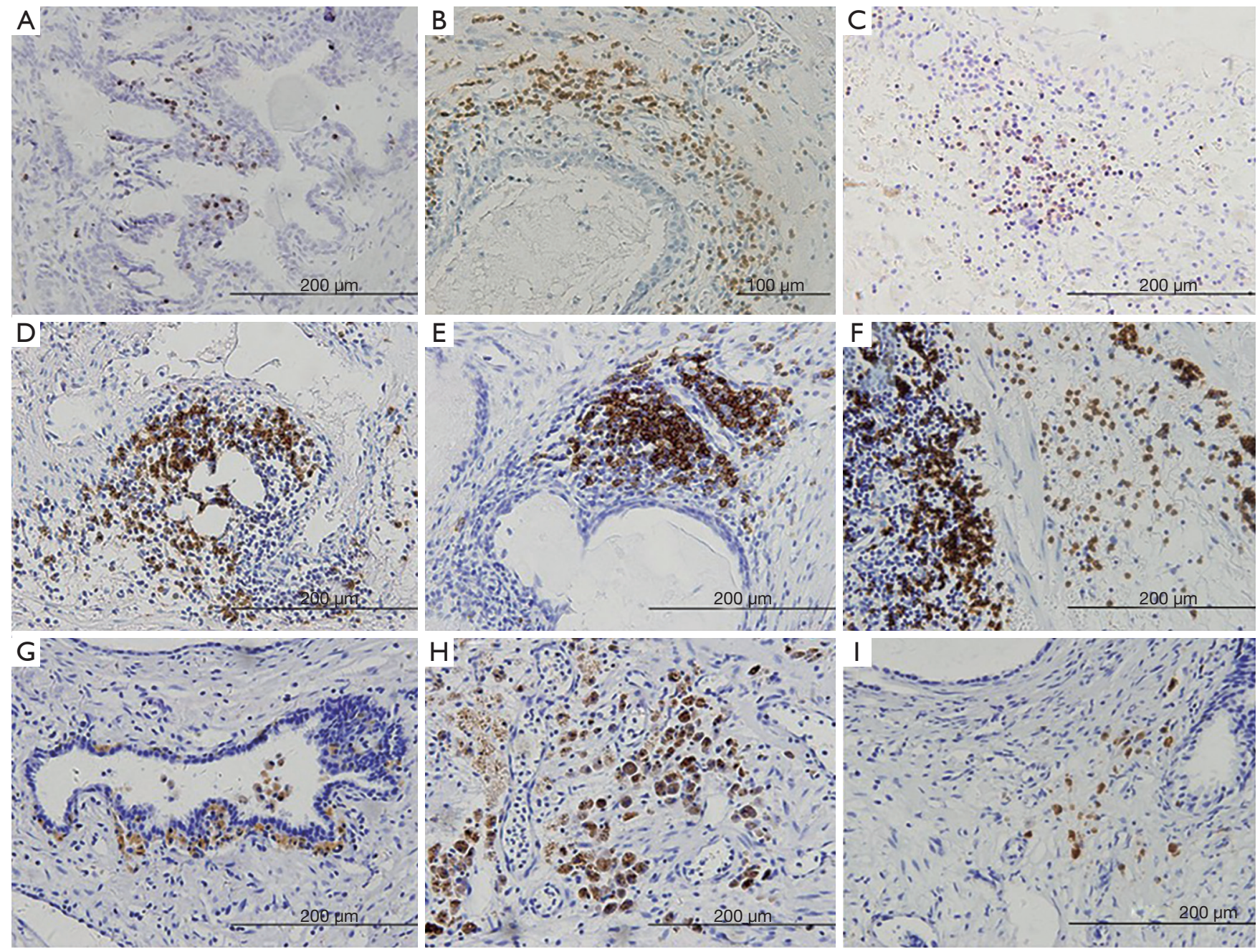

Figure 2 T-lymphocytes, B-lymphocytes and macrophages infiltration of varying degrees [CD3 staining in (A,B,C), CD20 staining in (D,E,F), CD68 staining in $(\mathrm{G}, \mathrm{H}, \mathrm{I})$; IHC, $\times 200]$. (A,B,C) T-lymphocytes infiltration: (A) glandular (in 27.6\% patients); (B) periglandular (in $77.6 \%$ patients); (C) stromal (in 55.3\% patients). (D,E,F) B-lymphocytes inflammation: (D) glandular (in 35.5\% patients); (E) periglandular (in $38.2 \%$ patients); (F) stromal (in 14.5\% patients). (G,H,I) Macrophages infiltration: (G) glandular (in 26.3\% patients); (H) periglandular (in $28.9 \%$ patients); (I) stromal (in $22.4 \%$ patients).

cell infiltration and prostate volume (Table S2). We found stromal T-lymphocytes infiltration had a trend of correlation with prostate volume $(\mathrm{P}=0.077)$, while periglandular macrophages infiltration had a trend of correlation with prostate volume $(\mathrm{P}=0.050)$.

\section{Inflammation and metabolism}

A central feature of obesity is systemic chronic inflammation (14). In the process of chronic inflammation of obese adipose tissue, a variety of immune cells are involved. Therefore, obesity may also affect the distribution of inflammatory cells in BPH (15). We divided patients into two groups according to whether they were overweight (BMI $>25 \mathrm{~kg} / \mathrm{m}^{2}$ ) (Table 4). We found that overweight patients had higher glandular inflammation infiltration rate in the prostate $(\mathrm{P}=0.010)$.

\section{Inflammation and serum PSA level}

Univariable regression analysis was used to compare total serum PSA level among the grades of each inflammatory 
Table 2 Comparison of the distribution of different inflammatory cells

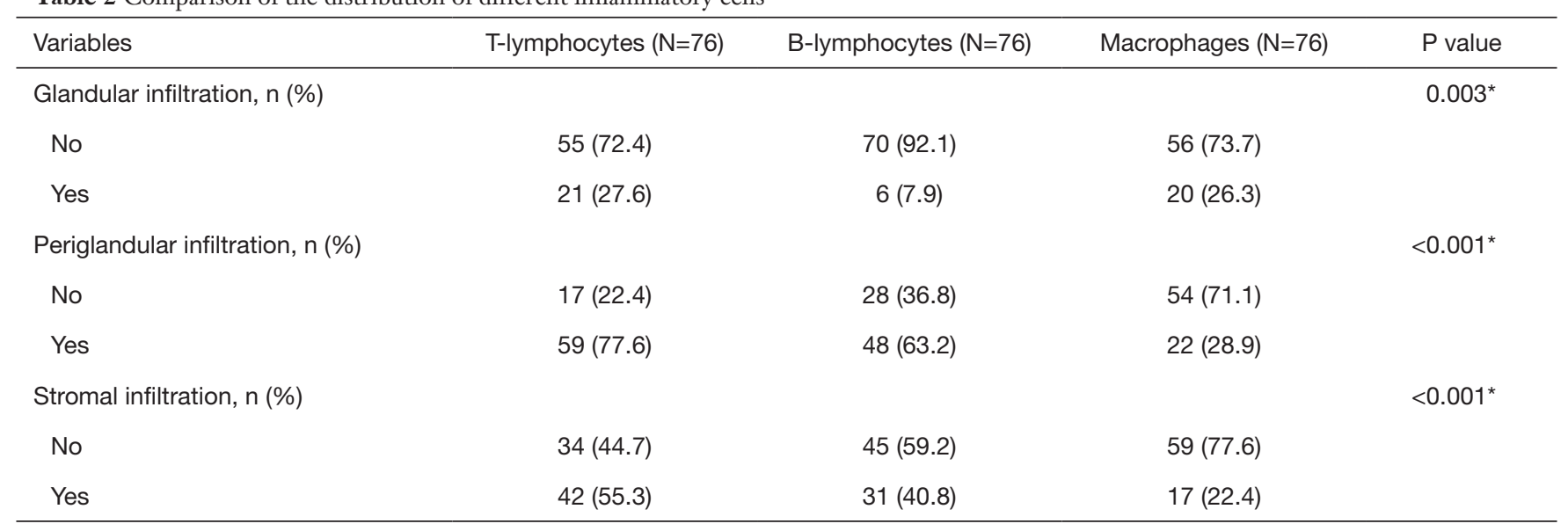

$P$ value was analyzed by Chi-square test analysis. ${ }^{*}, P<0.05$.

pattern, age, and prostate volume, which revealed total serum PSA level was significant associated with grading of glandular, periglandular and stromal inflammation, also with prostate volume. According to the multivariate analysis, the grade of glandular inflammation $(\mathrm{P}=0.031)$ could independently increase serum PSA level apart from the prostate volume (Table 5).

We also did further analysis to see if there was a relationship between the specific type of immune cell infiltration and serum PSA level (Table S3). We found glandular and periglandular T-lymphocytes infiltration were correlated with serum PSA level significantly $(\mathrm{P}=0.003$, 0.001 , respectively).

\section{Discussion}

Histologic inflammatory infiltration is a universal histopathology in prostatic specimens $(14,16)$. Our investigation revealed that all specimens derived from TURP surgery had histological inflammation, although all of our patients neither have clinical signs of prostatitis nor any correlation with urinary infection. Results from multicentric clinical trials such as REDUCE also showed histologic inflammation affected $77.6 \%$ of 8,224 patients respectively (17-19).

The frequently observed inflammatory cells in periglandular section indicate the genesis of immune response in prostate may proceed from this area. Epithelial injury could cause the periglandular tissue exposed to secretion products of the prostate which has a high proteolytic activity. They could destroy connective tissue cells and digest major matrix areas, allowing broad access of autoantigenic molecules to the immune system of the prostate $(15,20,21)$. Stimuli such as infectious agents or urinary reflux, metabolic syndrome, aging processes, and autoimmune responses can also cause prostatic immune dysregulation through the development of multiple molecular pathways involved in inflammatory infiltration (9). Therefore, BPH could be an immune inflammatory disease.

In our study, the predominant cell type in $\mathrm{BPH}$ tissue is T-lymphocytes, which was identified in $96.1 \%$ of all specimens, followed by B-lymphocytes in $77.6 \%$ and macrophages in $52.6 \%$ of all specimens. Previous studies revealed that inflammatory infiltrates consisted of $70 \%$ T-lymphocytes, $15 \%$ B-lymphocytes, and $15 \%$ macrophages $(20,22)$. The increased frequency and density of T-lymphocytes in $\mathrm{BPH}$ tissue suggested that the initial immune response in prostate might be cell-mediated immunity. Previous studies showed B-lymphocytes and macrophages probably participate in antigen presentation and autoimmune response (23-25).

Although previous studies revealed patients with prostatic inflammation had larger prostate volumes, higher International Prostate Symptom Score (IPSS) and greater risk of acute urinary retention than those without inflammation $(10,18,19,26)$, it is still unclear that which histologic section or immune cells subtype infiltration is relevant with prostate volume. In our study, the multiple regression analysis results showed age, degree of glandular and stromal inflammation would be the most important factors contributing to increased prostate volume. The aggressiveness of the glandular and stromal inflammation 


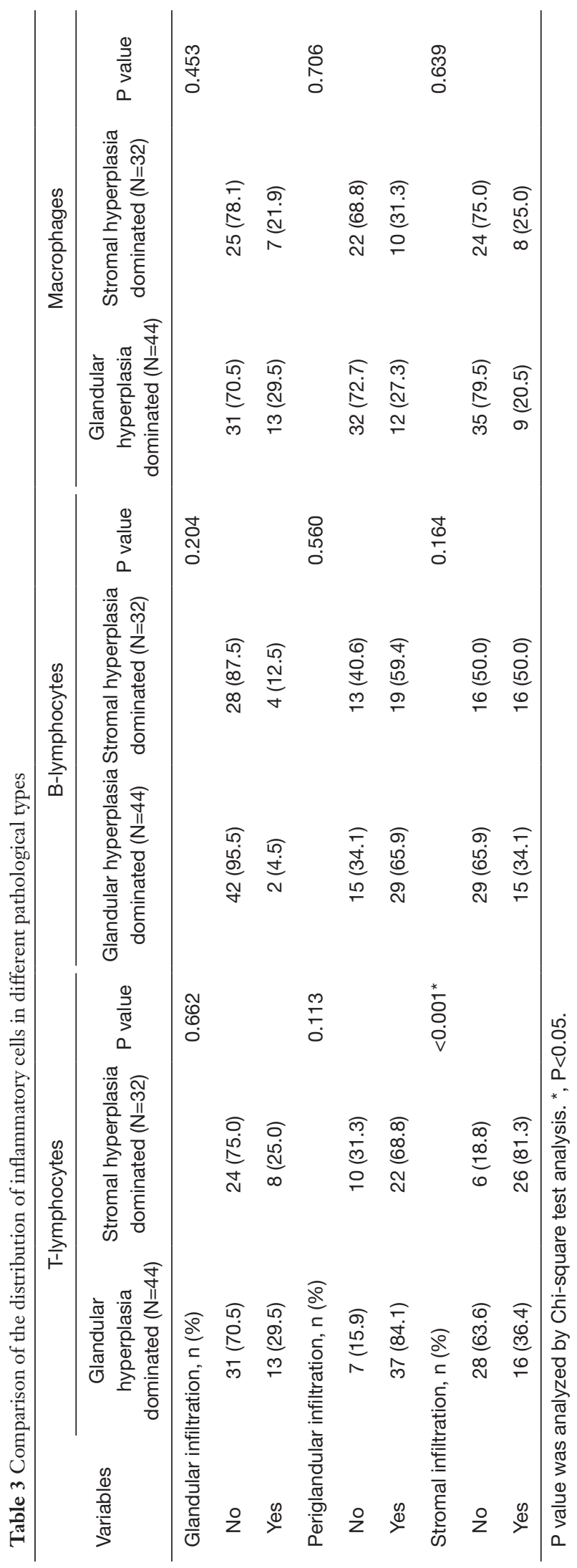

can cause tissue destruction and upregulated many proinflammatory cytokines. Inflammatory cells infiltration releases a number of cytokines and growth factors and induces tissue rebuilding and cellular proliferation. This wound-healing process could contribute to the prostate hyperplasia and might explain the pathogenesis of $\mathrm{BPH}$.

T-lymphocytes may be a key component in BPH. In vitro experiment showed activated T-lymphocytes from BPH tissues expressed significant amounts of proinflammatory cytokines and T cell-derived cytokines, such as IL-2, IL-4, IL-17 and interferon- $\gamma$, which caused the proliferation of BPH stromal cells (27-31). Also, stromal cells could express cytokine IL-15, which stimulate the growth of memory T-lymphocytes and maintain the T-lymphocytes infiltrate in $\mathrm{BPH}$ tissue, resulting in an increased recruitment of more T-lymphocytes into BPH stromal areas and proliferation of stromal cells (32).

Our study revealed stromal hyperplasia was significantly correlated with the degree of stromal inflammation and stromal T-lymphocytes infiltration, which reconfirmed the relationship between T-lymphocytes infiltration and stromal hyperplasia through the pathological and morphological phenomenon.

Epidemiological evidence suggests that prostatic inflammation associated with $\mathrm{BPH}$ is likely to be caused by metabolic stress signals, while obesity and metabolic syndrome may be associated with the development of $\mathrm{BPH}$ (33-35) and LUTS (36). In Tyagi et al.'s research, elevated urinary chemokines supported $\mathrm{BPH}$ as a metabolic disorder, suggesting a molecular link between BPH/LUTS and inflammation of the prostate (37).

Previous studies have pointed out that obesity itself is a chronic inflammatory state. Due to the changes of metabolism in obese patients, the systemic inflammatory state may be changed and might cause the increased prevalence of BPH (38). Our studies suggest that obese patients have increased prostate glandular inflammation infiltration. One possible reason is, obese patients have changed immune status, promoting the increase of inflammatory cells infiltration in prostate. Another possible reason is obese patients have more significant glandular changes in prostate, secreting more chemokines, and induce prostate inflammatory cells infiltration. Therefore, changes in the immune system and metabolism may be part of the reasons for prostate inflammation and BPH. More research is needed to confirm this relationship.

As we know, an increase in PSA is associated with aging and prostate volume. In addition to age and prostate 
volume, inflammatory cell infiltration may also be a factor in PSA elevation. Inflammation might be present in a significant proportion of patients with elevated serum PSA level $(39,40)$. Previous studies showed that the elevation of PSA levels was correlated with the glandular inflammatory infiltration (13). However, which type of immune cell is most responsible for the elevated serum PSA level was not mentioned. Our study showed grading of glandular inflammation and glandular T-lymphocytes infiltration were correlated with serum PSA level significantly.

The difference between Grade 0 and Grade 2 glandular inflammation did reach statistical significance. We assumed the prostate epithelium remains its integrity when the inflammation is mild (Grade 1). With the histologic aggressiveness grading of glandular inflammation, prostatic epithelial cells surrounding the affected area might be damaged and PSA stored in the epithelial cells released

Table 4 Relationship between obesity and the distribution of inflammatory cells in the prostate

\begin{tabular}{|c|c|c|c|}
\hline \multirow{2}{*}{ Variables } & \multicolumn{2}{|c|}{ Obesity } & \multirow{2}{*}{$P$ value } \\
\hline & No & Yes & \\
\hline Glandular inflammation & & & $0.010^{*}$ \\
\hline Mild & $40(85.1)$ & $17(58.6)$ & \\
\hline Moderate-severe & 7 (14.9) & $12(41.4)$ & \\
\hline Periglandular inflammation & & & 0.706 \\
\hline Mild & $19(40.4)$ & $13(44.8)$ & \\
\hline Moderate-severe & $28(59.6)$ & $16(55.2)$ & \\
\hline Stromal inflammation & & & 0.521 \\
\hline Mild & $24(51.1)$ & $17(58.6)$ & \\
\hline Moderate-severe & $23(48.9)$ & $12(41.4)$ & \\
\hline
\end{tabular}

$P$ value was analyzed by Chi-square test analysis. *, $P<0.05$. into the blood circulation result in the abnormal serum PSA elevation. Glandular T-lymphocytes infiltration plays an important role in disruption of the prostatic glandular epithelium (19). Total amount of T-lymphocytes in prostate might affect serum PSA level. There are more T-lymphocytes in the stroma than the gland, so the sampling error may lead to this bias.

The present study has some limitations. Firstly, prostatic hyperplasia mainly occurs in the transitional zone of the prostate gland, which is also the main area to be removed during TURP surgery. TURP excision tissue can be used to study inflammation of BPH (7). Meanwhile, the published literatures use the similar method to analyze the inflammatory condition of BPH tissues (7). But the limitations could not be ignored: the sampling method failed to exactly localize the inflammation condition on the transitional zone of the prostate. Secondly, we mainly studied the relationship between total inflammatory infiltration and clinical indicators, and the relationship between T-lymphocytes, B-lymphocytes and macrophages of inflammatory cells and clinical indicators. In the future, it is necessary to study the relationship between subtypes of inflammatory cells (M1/M2 macrophages, CD4/CD8 ${ }^{+}$ T-lymphocytes) and clinical indicators. Thirdly, as a singlecenter retrospective study, the sample size should be further increased in the future and multiple indicators should be analyzed to better describe the situation of inflammatory cells in BPH tissues.

\section{Conclusions}

We characterized infiltrated patterns of different inflammatory cells in histological structures of hyperplasic prostatic tissues from surgically treated $\mathrm{BPH}$ specimens. The role of inflammation in BPH development was

Table 5 Univariable and multiple regression analysis of total serum PSA level

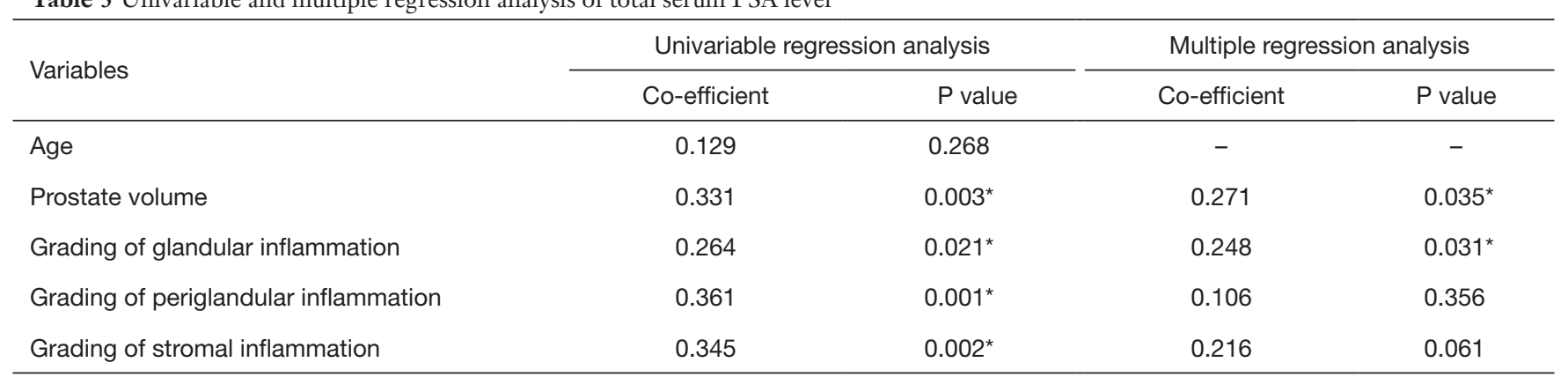

$\mathrm{P}$ value was analyzed by univariate or multivariate regression analysis. ${ }^{\star}, \mathrm{P}<0.05$. PSA, prostate-specific antigen. 
highlighted by its correlation with the prostate volume, metabolism and PSA level.

\section{Acknowledgments}

Funding: This study was supported by the Tibetan Natural Science Foundation (Grant No. XZ2017ZR-ZY019 to Yisen Meng) and the National Natural Science Foundation of China (Grant No. 81870518 to Wei Yu).

\section{Footnote}

Reporting Checklist: The authors have completed the STROBE reporting checklist. Available at http://dx. doi. org/10. 21037/tau-20-448

Data Sharing Statement: Available at http://dx.doi. org/10.21037/tau-20-448

Peer Review File: Available at http://dx. doi. org/10.21037/ tau-20-448

Conflicts of Interest: All authors have completed the ICMJE uniform disclosure form (available at http://dx. doi. org/10.21037/tau-20-448). The authors have no conflicts of interest to declare.

Ethical Statement: The authors are accountable for all aspects of the work in ensuring that questions related to the accuracy or integrity of any part of the work are appropriately investigated and resolved. This study was approved by the institutional ethics committee (NO.: 2018403) of our center. Patient records or information were anonymous and de-identified prior to analysis. Written informed consent was obtained from the patient for publication of this study and any accompanying images. This study was also in line with the Helsinki declaration (as revised in 2013).

Open Access Statement: This is an Open Access article distributed in accordance with the Creative Commons Attribution-NonCommercial-NoDerivs 4.0 International License (CC BY-NC-ND 4.0), which permits the noncommercial replication and distribution of the article with the strict proviso that no changes or edits are made and the original work is properly cited (including links to both the formal publication through the relevant DOI and the license). See: https://creativecommons.org/licenses/by-nc-nd/4.0/.

\section{References}

1. Chughtai B, Forde JC, Thomas DD, et al. Benign prostatic hyperplasia. Nat Rev Dis Primers 2016;2:16031.

2. Anderson JB, Roehrborn CG, Schalken JA, et al. The progression of benign prostatic hyperplasia: examining the evidence and determining the risk. Eur Urol 2001;39:390-9.

3. Chen Y, Yu W, Zhou L, et al. Relationship among diet habit and lower urinary tract symptoms and sexual function in outpatient-based males with LUTS/BPH: a multiregional and cross-sectional study in China. BMJ Open 2016;6:e10863.

4. Roehrborn CG. Pathology of benign prostatic hyperplasia. Int J Impot Res 2008;20 Suppl 3:S11-8.

5. Gandaglia G, Zaffuto E, Fossati N, et al. The role of prostatic inflammation in the development and progression of benign and malignant diseases. Curr Opin Urol 2017;27:99-106.

6. Vuichoud C, Loughlin KR. Benign prostatic hyperplasia: epidemiology, economics and evaluation. Can J Urol 2015;22 Suppl 1:1-6.

7. Sheng J, Yang Y, Cui Y, et al. M2 macrophage-mediated interleukin-4 signalling induces myofibroblast phenotype during the progression of benign prostatic hyperplasia. Cell Death Dis 2018;9:755.

8. Gandaglia G, Briganti A, Gontero P, et al. The role of chronic prostatic inflammation in the pathogenesis and progression of benign prostatic hyperplasia (BPH). BJU Int 2013;112:432-41.

9. De Nunzio C, Presicce F, Tubaro A. Inflammatory mediators in the development and progression of benign prostatic hyperplasia. Nat Rev Urol 2016;13:613-26.

10. Robert G, Descazeaud A, Nicolaïew N, et al. Inflammation in benign prostatic hyperplasia: a 282 patients' immunohistochemical analysis. Prostate 2009;69:1774-80.

11. Kramer G, Mitteregger D, Marberger $M$. Is benign prostatic hyperplasia $(\mathrm{BPH})$ an immune inflammatory disease? Eur Urol 2007;51:1202-16.

12. Nickel JC, True LD, Krieger JN, et al. Consensus development of a histopathological classification system for chronic prostatic inflammation. BJU Int 2001;87:797-805.

13. Mostofi FK, Davis CJ. Male reproductive system. In: Damjanov I, Linder J. Anderson's pathology. 10th edition. CRC Press, 1995.

14. JI E. The lower Urinary Tract and Male Genital System. In: Kumar V, Abbas A, Fausto N, et al. Robbins and Cotran Pathologic Basis of Disease. 8th edition. 
Philadelphia, USA: Saunders Elsevier Inc., 2010.

15. Blumenfeld $W$, Tucci $S$, Narayan P. Incidental lymphocytic prostatitis. Selective involvement with nonmalignant glands. Am J Surg Pathol 1992;16:975-81.

16. Nickel JC, Downey J, Young I, Boag S. Asymptomatic inflammation and/or infection in benign prostatic hyperplasia. BJU Int 1999;84:976-81.

17. Nickel JC, Roehrborn CG, O'Leary MP, et al. The relationship between prostate inflammation and lower urinary tract symptoms: examination of baseline data from the REDUCE trial. Eur Urol 2008;54:1379-84.

18. Nickel JC, Roehrborn CG, O'leary MP, et al. Examination of the relationship between symptoms of prostatitis and histological inflammation: baseline data from the REDUCE chemoprevention trial. J Urol 2007;178:896900; discussion 900-1.

19. Wang W, Bergh A, Damber JE. Chronic inflammation in benign prostate hyperplasia is associated with focal upregulation of cyclooxygenase-2, Bcl-2, and cell proliferation in the glandular epithelium. Prostate 2004;61:60-72.

20. Steiner GE, Stix U, Handisurya A, et al. Cytokine expression pattern in benign prostatic hyperplasia infiltrating T cells and impact of lymphocytic infiltration on cytokine mRNA profile in prostatic tissue. Lab Invest 2003;83:1131-46.

21. Ponniah S, Arah I, Alexander RB. PSA is a candidate selfantigen in autoimmune chronic prostatitis/chronic pelvic pain syndrome. Prostate 2000;44:49-54.

22. Theyer G, Kramer G, Assmann I, et al. Phenotypic characterization of infiltrating leukocytes in benign prostatic hyperplasia. Lab Invest 1992;66:96-107.

23. Ablin RJ, Gonder MJ, Soanes WA. Localization of immunoglobulins in human prostatic tissue. J Immunol 1971;107:603-4.

24. Roehrborn CG, Kaplan SA, Noble WD, et al. The impact of acute or chronic inflammation in baseline biopsy on the risk of clinical progression of BPE: Results from the MTOPS study. American Urological Association Meeting, 2005:abstract 1277.

25. Taoka R, Tsukuda F, Ishikawa M, et al. Association of prostatic inflammation with down-regulation of macrophage inhibitory cytokine-1 gene in symptomatic benign prostatic hyperplasia. J Urol 2004;171:2330-5.

26. Song L, Zhu Y, Han P, et al. A retrospective study: correlation of histologic inflammation in biopsy specimens of Chinese men undergoing surgery for benign prostatic hyperplasia with serum prostate-specific antigen. Urology
2011;77:688-92.

27. Kramer G, Steiner GE, Handisurya A, et al. Increased expression of lymphocyte-derived cytokines in benign hyperplastic prostate tissue, identification of the producing cell types, and effect of differentially expressed cytokines on stromal cell proliferation. Prostate 2002;52:43-58.

28. Steiner GE, Newman ME, Paikl D, et al. Expression and function of pro-inflammatory interleukin IL-17 and IL17 receptor in normal, benign hyperplastic, and malignant prostate. Prostate 2003;56:171-82.

29. Hobisch A, Rogatsch H, Hittmair A, et al.

Immunohistochemical localization of interleukin-6 and its receptor in benign, premalignant and malignant prostate tissue. J Pathol 2000;191:239-44.

30. Giri D, Ittmann M. Interleukin-8 is a paracrine inducer of fibroblast growth factor 2, a stromal and epithelial growth factor in benign prostatic hyperplasia. Am J Pathol 2001;159:139-47.

31. Penna G, Mondaini N, Amuchastegui S, et al. Seminal plasma cytokines and chemokines in prostate inflammation: interleukin 8 as a predictive biomarker in chronic prostatitis/chronic pelvic pain syndrome and benign prostatic hyperplasia. Eur Urol 2007;51:524-33; discussion 533.

32. Handisurya A, Steiner GE, Stix U, et al. Differential expression of interleukin-15, a pro-inflammatory cytokine and T-cell growth factor, and its receptor in human prostate. Prostate 2001;49:251-62.

33. Vignozzi L, Rastrelli G, Corona G, et al. Benign prostatic hyperplasia: a new metabolic disease? J Endocrinol Invest 2014;37:313-22.

34. Fowke JH, Koyama T, Fadare O, et al. Does Inflammation Mediate the Obesity and BPH Relationship? An Epidemiologic Analysis of Body Composition and Inflammatory Markers in Blood, Urine, and Prostate Tissue, and the Relationship with Prostate Enlargement and Lower Urinary Tract Symptoms. PLoS One 2016;11:e0156918.

35. Akin Y, Gulmez H, Ates E, et al. Preliminary assessment of Neck Circumference in Benign Prostatic Hyperplasia in Patients with Metabolic Syndrome. Int Braz J Urol 2017;43:95-103.

36. Motoya T, Matsumoto S, Yamaguchi S, et al. The impact of abdominal aortic calcification and visceral fat obesity on lower urinary tract symptoms in patients with benign prostatic hyperplasia. Int Urol Nephrol 2014;46:1877-81.

37. Tyagi P, Motley SS, Koyama T, et al. Molecular correlates in urine for the obesity and prostatic inflammation of 
BPH/LUTS patients. Prostate 2018;78:17-24.

38. Lokeshwar SD, Harper BT, Webb E, et al. Epidemiology and treatment modalities for the management of benign prostatic hyperplasia. Transl Androl Urol 2019;8:529-39.

39. Karazanashvili G, Managadze L. Prostate-specific antigen (PSA) value change after antibacterial therapy of prostate inflammation, as a diagnostic method for prostate cancer screening in cases of PSA value within 4-10 ng/ml and nonsuspicious results of digital rectal examination. Eur Urol 2001;39:538-43.

40. Terakawa T, Miyake H, Kanomata N, et al. Inverse association between histologic inflammation in needle biopsy specimens and prostate cancer in men with serum PSA of 10-50 ng/mL. Urology 2008;72:1194-7.

Cite this article as: Meng Y, Yu W, Liu Z, Zhang M, Chen Y, Li S, Fan Y, Hu S, Zhang K, Zhang Q, Jin J. The inflammation patterns of different inflammatory cells in histological structures of hyperplasic prostatic tissues. Transl Androl Urol 2020;9(4):16391649. doi: $10.21037 /$ tau-20-448 


\section{Supplementary}

Table S1 Classification of inflammatory infiltration in prostate

\begin{tabular}{ll}
\hline Classification & Description \\
\hline Localization & Histologic type \\
Glandular & Inflammatory cells infiltrate the glandular/ductal epithelium and/or lumen \\
Periglandular & Inflammatory cells infiltrate the stroma, centered on a gland/duct, less than $50 \mu \mathrm{m}$ from the gland/duct \\
Stromal & Inflammatory cells infiltrate the stroma, more than $50 \mu \mathrm{m}$ from the gland/duct \\
Extent & Tissue area involved by inflammatory cell infiltrates \\
Focal & $<10 \%$ \\
Multifocal & $10-50 \%$ \\
Diffuse & $>50 \%$ \\
Grade & $\begin{array}{l}\left.\text { Morphological description (density of inflammatory cells, number of cells/mm }{ }^{2}\right) \\
\text { 1/Mild }\end{array}$ \\
Isolated inflammatory cells, distributed in interstitial spaces (<100) \\
Inflammatory cells aggregate and appear in sheets, without tissue destruction or lymphoid nodules/follicular \\
f/Severe
\end{tabular}
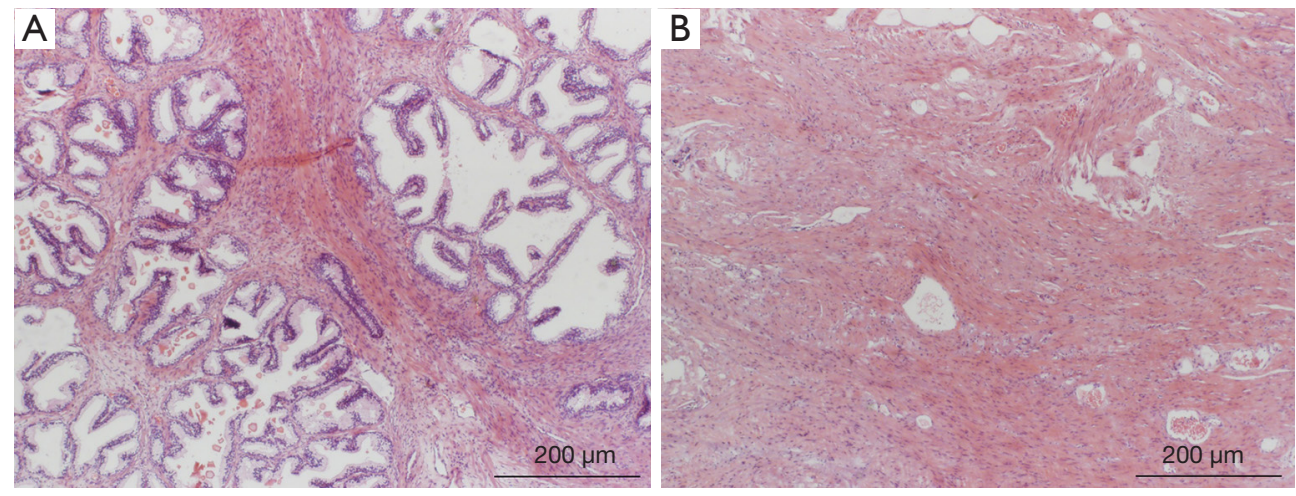

Figure S1 Representative histological photomicrographs of epithelial or stromal hyperplasia of BPH specimens (H\&E staining, $\times 100)$. In the epithelial hyperplasia-dominant BPH patients' tissue, tall columnar prostatic epithelial cells are often seen, with prominent hyperplasia protruding into the glandular cavity. There is a marked increase in glands with glandular (adenomatous) nodules or mixed nodules around the glands. In the stromal hyperplasia-dominant BPH patients' tissue, stromal thickening/nodules, adenomyoid-type nodules, or fibroadenoma type nodules are often seen. (A) Representative histological photomicrographs of epithelial hyperplasia; (B) representative histological photomicrographs of stromal hyperplasia. BPH, benign prostatic hyperplasia. 
Table S2 Further analysis on the association of different type of immune cell infiltration and prostate volume

\begin{tabular}{|c|c|c|c|c|c|c|c|c|c|}
\hline \multirow{2}{*}{ Variables } & \multicolumn{3}{|c|}{ T-lymphocytes } & \multicolumn{3}{|c|}{ B-lymphocytes } & \multicolumn{3}{|c|}{ Macrophages } \\
\hline & Number, n (\%) & Prostate volume $(\mathrm{mL})$ & $P$ value & Number, n (\%) & Prostate volume (mL) & $P$ value & Number, n (\%) & Prostate volume $(\mathrm{mL})$ & $P$ value \\
\hline \multicolumn{2}{|c|}{ Glandular infiltration } & & 0.393 & & & 0.558 & & & 0.218 \\
\hline No & $55(72.4)$ & 90.42 & & $70(92.1)$ & 91.50 & & $56(73.7)$ & 85.09 & \\
\hline Yes & $21(27.6)$ & 95.85 & & $6(7.9)$ & 96.83 & & $20(26.3)$ & 111.05 & \\
\hline \multicolumn{2}{|c|}{ Periglandular infiltration } & & 0.799 & & & 0.078 & & & 0.050 \\
\hline No & $17(22.4)$ & 90.45 & & $28(36.8)$ & 79.16 & & $54(71.1)$ & 83.69 & \\
\hline Yes & $59(77.6)$ & 92.35 & & $48(63.2)$ & 99.36 & & $22(28.9)$ & 112.13 & \\
\hline Stromal in & & & 0.077 & & & 0.977 & & & 0.924 \\
\hline No & $34(44.7)$ & 81.38 & & $45(59.2)$ & 92.06 & & $59(77.6)$ & 91.65 & \\
\hline Yes & $42(55.3)$ & 100.46 & & $31(40.8)$ & 91.73 & & $17(22.4)$ & 92.88 & \\
\hline
\end{tabular}

$P$ value was analyzed by $t$-test analysis.

Table S3 Further analysis on the association of different type of immune cell infiltration and total serum PSA level

\begin{tabular}{|c|c|c|c|c|c|c|c|c|c|}
\hline \multirow{2}{*}{ Variables } & \multicolumn{3}{|c|}{ T-lymphocytes } & \multicolumn{3}{|c|}{ B-lymphocytes } & \multicolumn{3}{|c|}{ Macrophages } \\
\hline & Number, n (\%) & Mean PSA & $P$ value & Number, n (\%) & Mean PSA & $P$ value & Number, n (\%) & Mean PSA & $P$ value \\
\hline Glandular infiltration & & & $0.003^{*}$ & & & 0.558 & & & 0.218 \\
\hline No & $55(72.4)$ & 4.83 & & $70(92.1)$ & 5.91 & & $56(73.7)$ & 5.96 & \\
\hline Yes & $21(27.6)$ & 8.57 & & $6(7.9)$ & 5.28 & & $20(26.3)$ & 5.58 & \\
\hline Periglandular infiltration & & & $0.001^{*}$ & & & 0.562 & & & 0.920 \\
\hline No & $17(22.4)$ & 4.59 & & $28(36.8)$ & 4.98 & & $54(71.1)$ & 5.59 & \\
\hline Yes & $59(77.6)$ & 6.23 & & $48(63.2)$ & 6.38 & & $22(28.9)$ & 6.53 & \\
\hline Stromal infiltration & & & 0.054 & & & 0.910 & & & 0.792 \\
\hline No & $34(44.7)$ & 5.07 & & $45(59.2)$ & 6.11 & & $59(77.6)$ & 5.78 & \\
\hline Yes & $42(55.3)$ & 6.50 & & $31(40.8)$ & 5.51 & & $17(22.4)$ & 6.16 & \\
\hline
\end{tabular}

$\mathrm{P}$ value was analyzed by $t$-test analysis. ${ }^{*}, \mathrm{P}<0.05$. PSA, prostate-specific antigen. 